\title{
ACTIVITIES OF THE VOLGOGRAD BRANCH OF ALL-RUSSIAN SOCIETY FOR PROTECTION OF HISTORICAL AND CULTURAL MONUMENTS ON THE PROTECTION OF LABOUR GLORY MONUMENTS OF THE SOVIET PEOPLE IN THE 1970S
}

\author{
Dmitriy N. Filatov \\ Volgograd State Socio-Pedagogical University, Volgograd, Russian Federation
}

\begin{abstract}
The article examines the causes and origins of the all-Russian society for protection of monuments of history and culture. On the basis of archival documents the author shows the appearance of the Volgograd branch of all-Russian society of protection of monuments of history and culture. The author describes its activities on studying, preserving and promoting the monuments of history and culture of the Volgograd region in the 1970s.

The author discusses the causes of establishing in 1974 the section of the regional Department for the protection and promotion of monuments of labour glory of the Soviet people. He indicates that its appearance in the structure of all-Russian society of protection of monuments of history and culture was associated with an increased conducted by the then government work on military-Patriotic education of youth. Under this policy, the section has been considered from the point of view of propaganda of Soviet history and focused on the identification, promotion and protection of monuments of history of Soviet society. The article studies its activities related to the identification, research, description, and preservation of monuments of labour achievements of the Soviet period. The author indicates the difficulties encountered after the adoption in 1976 of the USSR Law "On the protection and use of monuments of history and culture", where the monuments of labour glory in a separate category were not distinguished and were classified as historical monuments. The author describes the closure of the section of monuments to the labour of fame in 1979 and evaluates the results of the section, its contribution to the preservation of the cultural heritage of the Volgograd region.

Key words: Volgograd branch of all-Russian society of protection of monuments of history and culture, monuments of labour glory of the Soviet people, propaganda, history of the Soviet society, cultural heritage, protection of monuments.
\end{abstract}

\section{ДЕЯТЕЛЬНОСТЬ ВОЛГОГРАДСКОГО ОТДЕЛЕНИЯ ВООПИИК ПО ОХРАНЕ ПАМЯТНИКОВ ТРУДОВОЙ СЛАВЫ СОВЕТСКОГО НАРОДА В 1970-х ГОДАХ}

\author{
Дмитрий Николаевич Филатов \\ Волгоградский государственный социально-педагогический университет, \\ г. Волгоград, Российская Федерация
}


связано с усилением проводившейся тогда государством работы по военно-патриотическому воспитанию молодежи. Работа секции рассматривается с точки зрения пропаганды советской истории, где основное внимание уделялось поиску и охране памятников истории советского общества. Описывается ее деятельность, связанная с выявлением, изучением, описанием и сохранением памятников трудовых свершений советского периода. Указывается на возникшие у нее трудности после принятия в 1976 г. Закона СССР «Об охране и использовании памятников истории и культуры», где памятники трудовой славы в отдельную категорию не выделялись и были отнесены к памятникам истории. Описывается закрытие секции памятников трудовой славы в 1979 году. Оцениваются результаты работы секции, ее вклад в дело сохранения культурного наследия Волгоградской области.

Ключевые слова: Волгоградское отделение ВООПИиК, памятники трудовой славы советского народа, пропаганда, история советского общества, культурное наследие, охрана памятников.

Вновь возникший в последнее время в российском обществе интерес к своей истории актуализировал поиски решения проблем изучения и сохранения памятников истории и культуры. Деятельность Волгоградского отделения ВООПИиК, которое проводило работу по поиску, описанию, систематизации и охране объектов культурного наследия на территории Волгоградской области, представляет несомненный интерес. Это важно в современных условиях с точки зрения изучения положительных примеров по изучению и сохранению культурного наследия.

Всероссийское общество охраны памятников истории и культуры появилось как результат государственной политики использования общественных движений в деле сохранения объектов культурного наследия.

Для установления над ними контроля и придания организационных форм было принято Постановление Совета Министров РСФСР № 882 от 23 июля 1965 г. об организации «Добровольного общества по охране памятников», получившее название Всероссийского общества охраны памятников истории и культуры (далее - ВООПИиК) [12, с. 228].

Учредительный съезд общества состоялся в июле 1966 года. Председателем ВООПИиК был избран известный химик, академик И.В. Петрянов-Соколов. На съезде был принят устав, определяющий основной целью Общества «содействие государственным органам охраны памятников» и «привлечение к этому широких слоев населения» $[19$, с. 5].

В августе 1965 г. было создано и Волгоградское областное отделение ВООПИиК. Возглавил его Иван Степанович Шепелев доктор исторических наук, профессор, заведующий кафедрой истории России Волгоград- ского государственного педагогического института имени А.С. Серафимовича [14, л. 18].

При Президиуме областного отделения сразу были созданы следующие секции: исторической пропаганды, археологическая секция и секция по работе с молодежью [14, л. 16]. Впоследствии, с начала 1970-х гг., были созданы и другие: архитектурная, историческая, музыкальной культуры, памятников науки и техники и ряд других.

Тогда же была образована и действовавшая с 1974 по 1979 г. секция памятников трудовой славы советского народа, специально занимавшаяся выявлением, изучением, описанием и сохранением памятников трудовых свершений советского периода.

Появление этой секции в структуре ВООПИиК было связано не только с необходимостью следования основной идеологической установке того времени, требовавшей первостепенного внимания к выявлению, пропаганде и охране историко-культурных памятников революционной, боевой и трудовой славы советского народа. Немаловажное значение имело и то, что с середины 1960-х гг. усилилась работа по военно-патриотическому воспитанию молодежи [3, с. 37].

С 1965 г. в РСФСР в связи с важными историческими датами начали проводиться Всероссийские смотры памятников социалистического строительства, Октябрьской революции и Великой Отечественной войны, а также народных музеев революционной, боевой и трудовой славы советского народа. Эти смотры стали одной из новых форм привлечения общественности к решению задач по охране памятников $[10$, с. 80$]$. Они были рассчитаны на активизацию деятельности на местах с целью улучшения изучения, учета, ох- 
раны, пропаганды и благоустройства памятников, но не всех, а лишь тех, которые отражали идеи революции и социалистического строительства.

В смотрах участвовали и члены ВООПИиК. Они изучали и составляли летописи событий, выявляли новые памятники. При необходимости ремонт или консервацию памятников осуществляли комсомольские и молодежные отряды. Финансирование работ осуществлялось за счет средств Общества охраны памятников, которые складывались из ежегодно уплачиваемых членских взносов [19, с. 3]. Всего же за свою деятельность ВООПИиК вложило в реставрацию и благоустройство памятников не менее десяти с половиной миллиардов рублей своих собственных средств [8].

Для придания этой деятельности более целенаправленного характера 2-й съезд ВООПИиК в 1972 г. конкретизировал содержание такой категории, как памятники истории советского общества. К ним были отнесены, прежде всего, памятники, связанные с восстановлением народного хозяйства, и социалистические стройки первых пятилеток [9].

Охрана таких памятников становится приоритетным направлением в деятельности ВООПИиК, что было зафиксировано в новом Уставе Всероссийского общества охраны памятников истории и культуры, принятом 23 февраля 1973 г.: среди перечня всех видов памятников истории и культуры первыми назывались памятники историко-революционные, воинской и трудовой славы $[19$, с. 5$]$.

В выполнение поставленных задач включилось и Волгоградское отделение ВООПИиК. По его предложению 28 мая 1974 г. на заседании бюро Волгоградского обкома КПСС было принято постановление «Об улучшении работы по изучению, увековечению, сохранению памятников трудовой славы советского народа и их использовании в деле коммунистического воспитания трудящихся области». В нем говорилось, что данную работу должны проводить государственные и общественные организации. В этом также должны были участвовать кафедры общественных наук вузов города [13, л. 37].

Президиум Совета Волгоградского областного отделения ВООПИиК 18 июня 1974 г. утвердил план мероприятий по выполнению этого постановления. В соответствии с ним первичным организациям было дано задание на выявление, изучение, увековечение и активное использование в воспитательных целях памятников трудовой славы. А при Областном Совете была создана секция памятников трудовой славы советского народа. Ее председателем был избран член президиумов Центрального совета и Волгоградского областного совета ВООПИиК Н.С. Агринский [4, л. 9].

Секцией была проведена разработка письма с инструкциями о том, как должна проходить работа первичных организаций по выявлению, изучению и описанию памятников трудовой славы советского народа.

Всего в секции, созданной в июле 1974 г., было 17 человек. В ее состав входили ректор Волгоградского педагогического института М.М. Загорулько, доценты Н.С. Агринский, Н.Н. Демидов, С.М. Дроздов. Также там участвовали ветераны труда - дважды Герой Социалистического Труда П.В. Гвоздков, Герои Социалистического Труда М.Г. Головачев, Н.П. Логвин, В.П. Николаев и др. [4, л. 20].

При секции была создана лаборатория по проблеме охраны и пропаганды памятников трудовой славы, которая должна была заниматься разработкой критериев отбора памятников трудовой славы и составлением методики их описания.

Работа лаборатории с самого начала велась на общественных началах. Штат сотрудников формировался из сотрудников и студентов исторического факультета Волгоградского педагогического института. Они вели работу по выявлению, изучению и описанию памятников и памятных мест трудовой славы в городах и районах области, составляли исторические справки на памятники и памятные места трудовой славы, подлежащие увековечению.

В составе лаборатории были три секции: предприятий промышленности, транспорта и строительства; колхозов, совхозов и других сельскохозяйственных предприятий; просвещения, культуры и науки.

В своей научно-исследовательской работе лаборатория широко использовала литературные источники, материалы и фонды областного краеведческого музея, народных музеев, областного государственного и партий- 
ного архивов, фонды библиотек, а также материалы и документы районных отделов культуры и районных отделов Общества.

На основе их изучения в 1975 г. президиум областного совета ВООПИиК и Областное Управление культуры отобрали и утвердили перечень № 1 памятников трудовой славы, подлежащих изучению, описанию и увековечению.

Всего было отобрано 92 памятника, в том числе 28 предприятий промышленности, 28 колхозов и совхозов и 36 учреждений просвещения, культуры и науки. В этот перечень вошли объекты, построенные в период индустриализации, такие как Волгоградский тракторный завод имени Ф.Э. Дзержинского, металлургический завод «Красный Октябрь», Себряковский цементный завод имени П.А. Юдина, а также выделяющиеся из общего числа, например, Волго-Донской канал как самый длинный канал в Европе [5, л. 29].

Важное место при отборе памятников трудовой славы занимали исторические справки на перечисленные объекты. Их составлением занимались руководители предприятий, колхозов и учреждений культуры и искусства. В справки включались сведения по истории создания, описывался трудовой путь и достижения.

Поступающие с мест в областной совет исторические справки изучались членами секции и консультантами научно-исследовательской лаборатории. Большинство справок были написаны с соблюдением принципа достоверности и научной обоснованности [5, л. 32].

Всего же за 1975 г. областным отделением ВООПИиК было благоустроено 1500 памятников, прочитано 6560 лекций по охране памятников и проведено 1508 экскурсий по историческим местам $[15$, л. 2$]$

Также было проведено два областных смотра памятников истории советского общества и две научно-практических конференции, в том числе «Памятники трудовой славы и использование их в коммунистическом воспитании трудящихся» $[5$, л. 5].

В 1976 г. проводился смотр-конкурс районных и многотиражных газет, посвященный памятникам трудовой славы области и деятельности Областного отделения Общества. Всего же в областных, районных и многоти- ражных газетах на темы охраны и пропаганды памятников печаталось ежегодно не менее 20-40 статей [18, л. 55].

В 1976 г. было выявлено 110 памятников трудовой славы и составлено 29 карточек на них с описанием [16, л. 3]. А в областных газетах «Волгоградская Правда» и «Молодой Ленинец» было напечатано 15 статей, посвященных памятникам и памятным местам боевой и трудовой славы $[6$, л. 6$]$.

За 1977 г. было выявлено уже 127 памятников трудовой славы. Всего же Волгоградским отделением ВООПИиК за этот год было благоустроено 677 памятников [17, л. 2].

Необходимо отметить, что работа секции памятников трудовой славы в Волгоградской области с самого начала была успешной, особенно в организации работы по выявлению, изучению, описанию и увековечению памятников и памятных мест трудовой славы.

Это было оценено Центральным советом ВООПИиК, который 14 октября 1974 г. разослал всем президиумам Советов АССР, краевых и областных отделений Общества письмо, в котором рекомендовал использовать опыт Волгоградского областного отделения по выявлению, изучению и сохранению памятников трудовой славы советского народа [4, с. 20].

Но успешно начавшая свою работу секция по охране и пропаганде памятников трудовой славы советского народа просуществовала недолго.

В принятом 29 октября 1976 г. Законе СССР «Об охране и использовании памятников истории и культуры» получили дальнейшее развитие правовые основы охраны памятников истории и культуры. Это предполагало приведение в соответствие с новым законом сушествовавшей уже нормативной базы и всей деятельности по охране памятников. В первой статье закона была дана научная классификация памятников истории и культуры, памятники трудовой славы в отдельную категорию не выделялись и были отнесены к памятникам истории [1]. Это положение повторялось и в Законе РСФСР от 15 декабря 1978 года «Об охране и использовании памятников истории и культуры» [2].

Это сказалось на деятельности секции по охране памятников трудовой славы. Так, в 1978 г. в исполком областного Совета депута- 


\section{ОТЕЧЕСТВЕННАЯ ИСТОРИЯ}

тов был передан материал на 40 объектов для принятия решения об их увековечении как памятников трудовой славы. Но исполком отказался принимать решение по этому вопросу, и прежде всего потому, что в Законах «Об охране и использовании памятников истории и культуры» не было такого определения, как памятники трудовой славы [7, л. 7].

И в 1979 г. секция пропаганды памятников трудовой славы была объединена с секцией исторических памятников. Она и продолжила работу по выявлению памятников на территории Волгоградской области. А работа по выявлению и увековечению памятников трудовой славы как отдельное направление постепенно прекратилась [11, л. 7].

За период своего существования секция по охране и пропаганде памятников трудовой славы первой начала изучение и учет на научной основе объектов культурного наследия. Она провела разработку методики составления исторических справок. Тщательно составленные справки включали в себя историю создания, внешний вид и состояние памятников. Были составлены карточки на многие объекты. Это впоследствии использовалось секцией исторических памятников и способствовало первичному учету и паспортизации памятников и памятных мест Волгоградской области.

Таким образом, деятельность секции по охране и пропаганде памятников трудовой славы советского народа принесла несомненную пользу по сохранению культурного наследия.

\section{СПИСОК ЛИТЕРАТУРЫ}

1. Ведомости Верховного Совета СССР. 1976. - № 44. - Ст. 628. - С. 728.

2. Ведомости Верховного Совета РСФСР. 1978. - № 51. - Ст. 1387. - С. 920.

3. Военно-патриотическое воспитание и подготовка молодежи к военной службе: история и современность / Р. В. Балашов [и др.]. - М. : Изд-во ДОСААФ России, 2010. $-75 \mathrm{c}$.

4. Годовой отчет о работе Волгоградского областного отделения ВООПИК за 1974 год// Центр Документации Новейшей Истории Волгоградской Области (далее - ЦДНИВО). - Ф. Р. 6911. -Оп. 1. Д. 49. - Л. 9, 20.

5. Годовой отчет о работе Волгоградского областного отделения ВООПИК за 1975 год // ЦДНИВО. Ф. Р. 6911.-Оп. 1. - Д. 57. - Л. 5, $29,32$.
6. Годовой отчет о работе Волгоградского областного отделения ВООПИК за 1976 год // ЦДНИВО. Ф. Р. 6911. - Оп. 1. - Д. 66. - Л. 6.

7. Годовой отчет о работе Волгоградского областного отделения ВООПИК за 1978 год // ЦДНИВО. Ф. Р. 6911.- Оп. 1. - Д. 81. - Л. 7.

8. Корольков, Н. К. Воспоминания из книги «Никто не освобождал нас от памяти» / Н. К. Корольков. М. : ВООПИиК, 2000. - Электрон. текстовые дан. - Режим доступа: http://russist.ru/biblio/ sborniky/sz/1/18.htm (дата обращения: 19.03.2016).Загл. с экрана.

9. Материалы II съезда ВООПИК (г. Ленинград, 4-6 июля 1972 г.). - М. : Изд-во Сов. Россия, 1973. $-191 \mathrm{c}$.

10. Медведева, Т. Н. Опыт проведения в РСФСР смотров памятников истории и культуры советского общества в 1965-1977 гг. / Т. Н. Медведева // Вопросы охраны, реставрации и пропаганды памятников истории и культуры : тр. НИИ культуры. - 1980. Вып. 93. - С. 60-80.

11. Отчет о работе Волгоградского областного отделения ВООПИК за 2-ое полугодие 1980 года // ЦДНИВО. - Ф. Р. 6911. - Оп. 1. - Д. 96. - Л. 7.

12. Постановления Совета Министров РСФСР за июль 1965 года (№ 804-900). - М. : Изд-во УПравделами Совета Министров РСФСР, 1965. - 297 с.

13. Протокол заседания бюро обкома КПСС № 10 // ЦДНИВО. - Ф. 113. - Оп. 92. - Д. 34. - Л. 37.

14. Решения 2-й отчетно-выборной конференции Волгоградского Отделения ВООПИК // ЦДНИВО. Ф. Р. 6911.- Оп. 1. - Д. 1. - Л. 16, 18.

15. Сводный статистический отчет о работе Волгоградского областного отделения ВООПИК за 1975 год // ЦДНИВО. - Ф. Р. 6911. - Оп. 1. Д. $58 .-$ Л. 2.

16. Сводный годовой отчет о работе Волгоградского областного отделения ВООПИК за 1976 год // ЦДНИВО. - Ф. Р. 6911. - Оп. 1. - Д. 67. - Л. 3.

17. Сводный годовой отчет о работе Волгоградского областного отделения ВООПИК за 1977 год // ЦДНИВО. - Ф. Р. 6911. - Оп.1. - Д. 74. - Л. 2.

18. Справка о работе Волгоградского областного отделения ВООПИК по выполнению решений XXV съезда КПСC, решений II-го съезда Общества за период с 1973 по 1975 год // ЦДНИВО. Ф. Р. 6911. - Оп. 1. - Д. 39. - Л. 55.

19. Устав Всероссийского общества охраны памятников истории и культуры. - М. : Изд-во Ротапринт ЭТПК, 1975. - $16 \mathrm{c}$.

\section{REFERENCES}

1. Vedomosti Verkhovnogo Soveta SSSR, 1976, no. 44 , art. 628. p. 728. 
2. Vedomosti Verkhovnogo Soveta RSFSR, 1978, no. 51, art. 1387 , p. 920.

3. Balashov R.V., et al. Voenno-patrioticheskoe vospitanie $i$ podgotovka molodezhi $k$ voennoy sluzhbe: istoriya i sovremennost [Military and Patriotic Education and Training of Youth for Military Service: History and Modernity]. Moscow, Izd-vo DOSAAF Rossii Publ., 2010. 75 p.

4. Godovoy otchet o rabote Volgogradskogo oblastnogo otdeleniya VOOPIK za 1974 god [The Annual Report on Work of the Volgograd Regional Branch of All-Russian Society for Protection of Historical and Cultural Monuments for 1974]. Tsentr Dokumentatsii Noveyshey Istorii Volgogradskoy Oblasti [Center of Documentation of the Contemporary History of the Volgograd Region], F. R. 6911, Op.1, D. 49, L. 9, 20 .

5. Godovoy otchet o rabote Volgogradskogo oblastnogo otdeleniya VOOPIK za 1975 god [The Annual Report on Work of the Volgograd Regional Branch of All-Russian Society for Protection of Historical and Cultural Monuments for 1975]. Tsentr Dokumentatsii Noveyshey Istorii Volgogradskoy Oblasti [Center of Documentation of the Contemporary History of the Volgograd Region], F. R. 6911, Op.1, D. 57, L. 5, 29, 32 .

6. Godovoy otchet o rabote Volgogradskogo oblastnogo otdeleniya VOOPIK za 1976 god [The Annual Report on Work of the Volgograd Regional Branch of All-Russian Society for Protection of Historical and Cultural Monuments for 1976]. Tsentr Dokumentatsii Noveyshey Istorii Volgogradskoy Oblasti [Center of Documentation of the Contemporary History of the Volgograd Region], F. R. 6911, Op.1, D. 66, L. 6 .

7. Godovoy otchet o rabote Volgogradskogo oblastnogo otdeleniya VOOPIK za 1978 god [The Annual Report on Work of the Volgograd Regional Branch of All-Russian Society for Protection of Historical and Cultural Monuments for 1978]. Tsentr Dokumentatsii Noveyshey Istorii Volgogradskoy Oblasti [Center of Documentation of the Contemporary History of the Volgograd Region], F. R. 6911, Op. 1, D. 81, L. 7 .

8. Korolkov N.K. Vospominaniya iz knigi "Nikto ne osvobozhdal nas ot pamyati" [Memoirs From the Book "Nobody Exempted Us From Memory"]. Moscow, VOOPIiK Publ., 2000. Available at: http://russist.ru/ biblio/sborniky/sz/1/18.htm. (accessed March 19, 2016).

9. Materialy II syezda VOOPIK (g. Leningrad, 4-6 iyulya 1972 g.) [Proceedings of the 2 nd Congress of All-Russian Society for Protection of Historical and Cultural Monuments (Leningrad, July 4-6, 1972)]. Moscow, Izd-vo Sov. Rossiya, 1973. 191 p.

10. Medvedeva T.N. Opyt provedeniya v RSFSR smotrov pamyatnikov istorii i kultury sovetskogo obshchestva v 1965-1977 gg. [Experience of Carrying Out Reviews of Historical and Cultural Monuments of the Soviet Society in 1965-1977 in RSFSR]. Voprosy okhrany, restavratsii $i$ propagandy pamyatnikov istorii i kultury: tr. NII kultury, 1980, iss. 93, pp. 60-80.

11. Otchet o rabote Volgogradskogo oblastnogo otdeleniya VOOPIK za 2-oe polugodie 1980 goda [The Report on Work of the Volgograd Regional Office of the All-Russian Society for Protection of Historical and Cultural Monuments for the 2nd Half-Year of 1980]. Tsentr Dokumentatsii Noveyshey Istorii Volgogradskoy Oblasti [Center of Documentation of the Contemporary History of the Volgograd Region], F.R. 6911, Op.1, D. 96, L. 7.

12. Postanovleniya Soveta Ministrov RSFSR za iyul 1965 goda (№ 804-900) [Resolution of the RSFSR Council of Ministers for July 1965 (no. 804-900)]. Moscow, Izd-vo Upravdelami Soveta Ministrov RSFSR, 1965. 297 p.

13. Protokol zasedaniya byuro obkoma KPSS № 10 [The Minutes of the Meeting of the Bureau of Regional Committee of the Communist Party of the Soviet Union no. 10]. Tsentr Dokumentatsii Noveyshey Istorii Volgogradskoy Oblasti [Center of Documentation of the Contemporary History of the Volgograd Region], F. 113, Op. 92, D. 34, L. 37.

14. Resheniya 2-y otchetno-vybornoy konferentsii Volgogradskogo Otdeleniya VOOPIK [Decision of the 2nd Report and Election Conference of the Volgograd Regional Office of All-Russian Society for Protection of Historical and Cultural Monuments]. Tsentr Dokumentatsii Noveyshey Istorii Volgogradskoy Oblasti [Center of Documentation of the Contemporary History of the Volgograd Region], F.R. 6911, Op. 1, D. 1, L. 16,18.

15. Svodnyy statisticheskiy otchet o rabote Volgogradskogo oblastnogo otdeleniya VOOPIK za $1975 \operatorname{god}$ [A Summary Statistical Report on the Work of the Volgograd Regional Office of All-Russian Society for Protection of Historical and Cultural Monuments for 1975]. Tsentr Dokumentatsii Noveyshey Istorii Volgogradskoy Oblasti [Center of Documentation of the Contemporary History of the Volgograd Region], F.R. 6911, Op. 1, D. 58, L. 2.

16. Svodnyy otchet o rabote Volgogradskogo oblastnogo otdeleniya VOOPIK za 1976 god [A Summary Report on the Work of the Volgograd Regional Office of All-Russian Society for Protection of Historical and Cultural Monuments for 1976]. Tsentr Dokumentatsii Noveyshey Istorii Volgogradskoy Oblasti [Center of Documentation of the Contemporary History of the Volgograd Region], F.R. 6911, Op. 1, D. 67, L. 3 .

17. Svodnyy otchet o rabote Volgogradskogo oblastnogo otdeleniya VOOPIK za 1977 god [A Summary Report on the Work of the Volgograd 


\section{ОТЕЧЕСТВЕННАЯ ИСТОРИЯ}

Regional Office of All-Russian Society for Protection of Historical and Cultural Monuments for 1977]. Tsentr Dokumentatsii Noveyshey Istorii Volgogradskoy Oblasti [Center of Documentation of the Contemporary History of the Volgograd Region], F.R. 6911, Op. 1, D. 74, L. 2 .

18. Spravka o rabote Volgogradskogo oblastnogo otdeleniya VOOPIK po vypolneniyu resheniy XXV syezda KPSS, resheniy II-go syezda Obshchestva za period s 1973 po 1975 god [The Record of Work of the Volgograd Regional Office of All-Russian Society for Protection of Historical and Cultural Monuments on Implementation of Decisions of the $25^{\text {th }}$ Congress of the CPSU, and the Decisions of the $2^{\text {nd }}$ Congress of the Community for the Period From 1973 to 1975.] Tsentr Dokumentatsii Noveyshey Istorii Volgogradskoy Oblasti [Center of Documentation of the Contemporary History of the Volgograd Region], F.R. 6911, Op.1, D. 39 , L. 55.

19. Ustav Vserossiyskogo obshchestva okhrany pamyatnikov istorii i kultury [Statute of the AllRussian Society for Protection of Historical and Cultural Monuments]. Moscow, Izd-vo Rotaprint ETPK, 1975. 16p.

\section{Information About the Author}

Dmitriy N. Filatov, Postgraduate Student, Department of History of Russia, Volgograd State Socio-Pedagogical University, Prosp. Lenina, 27, 400066 Volgograd, Russian Federation, filatov_dn@mail.ru.

\section{Информация об авторе}

Дмитрий Николаевич Филатов, аспирант кафедры истории России, Волгоградский государственный социально-педагогический университет, просп. им. В.И. Ленина, 27, 400066 г. Волгоград, Российская Федерация, filatov_dn@mail.ru. 